\title{
O INCIDENTE DE RESOLUÇÃO DE DEMANDAS REPETITIVAS E AS RELAÇÕES DE CONSUMO: Análise empírica da viabilidade jurídica //
}

Lucas do Monte Silva ${ }^{1}$

\section{Palavras-chave}

incidente de resolução de demandas repetitivas / direito do consumidor / dano moral / plano de saúde / análise empírica do Judiciário

HIIIIIIIIIIIIIIIIIIIIIIIIIIIIIII

\section{Sumário}

\section{Introdução}

2 As demandas repetitivas e os planos de saúde

3 Análise empírica dos casos de dano moral e o consumidor do plano de saúde: estudo de caso do Tribunal de Justiça de Santa Catarina

3.1 Apontamentos metodológicos

3.2 Dados do Tribunal de Justiça de Santa Catarina

3.3 Sobre a possibilidade da implicação dos incidentes de demandas repetitivas nos casos em análise

4 Conclusão

5 Referências

\section{Resumo}

Diante do cenário de massificação de demandas judiciais, o presente artigo pretende analisar os principais argumentos e questionamentos das demandas relacionadas aos danos morais e aos planos de saúde, no Tribunal de Justiça de Santa Catarina (TJSC), de forma a analisar a possível aplicação do incidente de resolução de demandas repetitivas, previsto no Código de Processo Civil, nesses casos. Para tanto, será realizada, primeiramente, uma análise do contexto atual do Poder Judiciário Brasileiro, apresentando o contexto de demandas repetitivas e massificação de contratos, bem como aspectos introdutórios do incidente de resolução de demandas repetitivas. Em seguida, será feita uma análise empírica jurisprudencial, quantitativa e qualitativa, do Tribunal de Justiça de Santa Catarina, realizando um estudo do tipo analítico transversal das demandas relacionadas ao tema, de forma a apresentar uma "radiografia argumentativa" dos acórdãos da referida Corte. Conclui-se pela possibilidade da aplicação do IRDR nas demandas repetitivas relativas aos temas sob análise, com as devidas cautelas legais, levando em consideração o alto número de questões de fato que envolvem demandas judiciais que possuem, entre seus pedidos, indenização por dano moral. 


\section{THE INCIDENT OF REPETITIVE CLAIMS RESOLUTION IN}

CONSUMER AFFAIRS: Empirical analysis of legal feasibility // Lucas do

\section{Monte Silva}

\section{Keywords}

incident of repetitive demands resolution / consumer's law / moral damage / health insurance / empirical analysis of the Judiciary

\begin{abstract}
Faced with the scenario of massification of lawsuits, this article intends to analyze the main arguments and questionings of the claims related to moral damage and health insurance plans, in the. The goal of this analysis was to understand the application of the incident of repetitive claims resolution of the new Civil Procedure Code. Thus, we conducted an analysis of the current context of the Brazilian judiciary, presenting the scenario of repetitive claims and massification of contracts and introductory aspects of the incident of repetitive claims resolution. Then, we performed a quantitative and qualitative empirical analysis, through a case study of the State of Santa Catarina Appel's Court. We used a cross descriptive analysis of the claims in order to demonstrate an 'argumentative radiography' of the judgments of the Court. The results confirmed the possibility of applying IRDR in repetitive claims relating to subjects of the study, with due legal caution, taking into account the high number of "issues of fact" that involve lawsuits that have, among their claims, compensation for moral damages.
\end{abstract}




\section{Introdução}

A morosidade do Poder Judiciário brasileiro não é novidade. Trata-se de temática que, apesar de já bastante discutida, vem nos últimos anos logrando maior monta na discussão jurídica. Primeiramente, com 0 art. $5^{\circ}$, LXXVIII, acrescentado pela Emenda Constitucional no 45/2004, da Constituição da República, que dispõe e garante a duração razoável do processo. Em seguida, com alterações nos textos legais, como, a título de exemplo, a adoção do modelo de processo sincrético, novas formas de cumprimento de sentença, uso de astreintes e, sobretudo, com a promulgação do Novo Código de Processo Civil, que cria o incidente de resolução de demandas repetitivas (IRDR) em seu art. 975. Segundo o referido artigo, é cabivel a instauração do IRDR quando houver, simultaneamente, efetiva repetição de processos que contenham controvérsia sobre a mesma questão unicamente de Direito (inciso I) e risco de ofensa à isonomia e à segurança jurídica (inciso II). Trata-se, assim, de instrumento que visa combater a litigiosidade em massa que ocorre no Brasil.

Um dos principais fatores dessa morosidade é atribuído às demandas repetitivas, que são aquelas demandas rotineiras/seriais, em que os argumentos e soluções apresentados nos processos se repetem, de maneira que não é raro o uso de petições e decisões padrões sobre a temática em apreciação.

Os principais responsáveis por essas demandas repetitivas são os fornecedores de relações de consumo, isto é, empresas de telecomunicação, instituições financeiras, redes de supermercados, planos de saúde, dentre outros, que devido à ambiguidade dos contratos de adesão utilizados em suas atividades, a recusa a realizar determinadas obrigações e respeitar os direitos do consumidor, acabam se tornando demandados em ações judiciais.

Com efeito, o presente estudo tem como objetivo verificar a possibilidade de aplicação do IRDR em casos relativos a pedido de indenização por dano moral, devido à recusa de atendimento por planos de saúde.

Para tanto, primeiramente, será realizada uma análise do contexto atual do Poder Judiciário Brasileiro, apresentando o contexto de demandas repetitivas e massi- ficação de contratos, bem como aspectos introdutórios do incidente de resolução de demandas repetitivas.

Em seguida, será feita uma análise empírica jurisprudencial, quantitativa e qualitativa, por meio de estudo de caso do Tribunal de Justiça de Santa Catarina, realizando um estudo empírico do tipo analítico transversal das demandas relacionadas ao tema mencionado, de forma a demonstrar uma "radiografia argumentativa" ${ }^{2}$ dos acórdãos do TJSC. 0 tipo de pesquisa é analítico, pois, a partir da amostra de acórdãos analisados, busca-se fazer inferições e testar a hipótese central da pesquisa, e transversal, tendo em vista que, baseado no recorte adotado, pretende-se verificar os principais argumentos das Cortes, através da observação direta das variáveis, nos moldes de uma "fotografia argumentativa" da situação atual do Tribunal.

Por meio dessa "radiografia argumentativa", pretende-se analisar a linearidade decisória e os tipos de argumentos que estão sendo apreciados pelo TJSC, em sede recursal, de modo a verificar se, considerando o "raio $x$ " dessa investigação, seria possível a aplicação do IRDR em tais casos.

Conclui-se que é possível a aplicação do IRDR nos casos sob análise, no entanto, sendo necessário ressaltar algumas peculiaridades que poderão fazer com que tal instrumento processual não tenha a eficácia desejada, destacando-se, por oportuno, o alto número de questões de fato, como, por exemplo, a fixação dos valores do dano moral, que podem mitigar o impacto desse incidente que tem como foco questões unicamente de direitos.

\section{As demandas repetitivas e os planos de saúde}

São mais de 74 milhões de processos judiciais em tramitação no Poder Judiciário brasileiro (CNJ, 2016). Um aumento de acervo processual em cerca de 1,9 milhão de processos em relação ao ano anterior (CNJ,

2 Trata-se de expressão ("radiografia argumentativa") utilizada pelo processualista Dierle Nunes. Cf. Nunes \& Bahia. Precedentes no CPC-2015: por uma Compreensão Constitucionalmente Adequada do seu uso no Brasil. Revista do Ministério Público do Rio de Janeiro, Rio de Janeiro, n. 57, jul./set. 2015. 
2016). Tais processos que, por sua vez, são julgados por 11.807 juízes estaduais (CNJ, 2016), 3.600 juízes do trabalho (CNJ, 2016), 1.654 magistrados federais (CJF, 2016) e 42 magistrados da Justiça Militar estadual (CNJ, 2016). ${ }^{3}$ A carga processual é tão volumosa que apenas para julgar todos os processos já peticionados no Poder Judiciário, zerando o número de processos e interrompendo o input de novas demandas durante esse período, seriam necessários mais de três anos para que esse objetivo fosse alcançado. ${ }^{4}$

Essa grande quantidade de processos decorre, sobretudo, da "explosão de litigiosidade", ocasionada por um conjunto de fatores que, cumulativamente, auxiliam para a ocorrência do presente cenário. Cita-se, por exemplo, o crescimento da população brasileira; o aumento de renda per capita e, consequentemente, um maior número de consumidores; a padronização dos contratos de obtenção de serviços (contratos de adesão); a potencialização e o incentivo ao acesso à justiça, não apenas sob o ponto de vista formal, mas também substancial, capitaneado pela Constituição da República de 1988; o aumento da quantidade de advogados, tribunais e faculdades de direito (Bochenek, 2013). Tais fatores são relevantes e fazem parte das ondas democratizantes e constitucionalistas responsáveis pelo aumento da procura do Judiciário (Bochenek, 2013).

Trata-se de uma temática que já possui vasta literatura, principalmente após a Reforma do Judiciário (EC n 45, de 2004), com relevantes contribuições, seja do Conselho Nacional de Justiça (CNJ, 2011), seja dos Tribunais de Justiça e Tribunais Regionais Federais

3 Relevante destacar que "a simples análise dos dados numéricos não mostra a realidade exata dos países, pois a lógica judicial e organizacional é diferente entre eles. Nesse sentido, ao orçamento destinado ao Poder Judiciário, ao número de juízes e à quantidade de advogados devem ser agregados outros elementos analíticos que não aparecem nas estatísticas. Ainda assim, o conhecimento quantitativo dessas variáveis é importante para a análise da efetividade do processamento de ações pelos Poderes Judiciários" (CNJ, 2011, p. 9). Nesse sentido, para uma visão sob a óptica da magistratura, ver Sadek (2016) e Sadek (2009).

4 Tal indicador foi apresentado em palestra do conselheiro do CNJ, Rubens Curado, sobre Processo Judicial Eletrônico, no II Seminário de Planejamento Estratégico Sustentável do Poder Judiciário, realizado no auditório Externo do Superior Tribunal de Justiça no dia 28 de maio de 2015, disponibilizado por via eletrônica. Disponível em: <https://www.youtube.com/watch?v=FAyFs-vfS6Y> .
(CJF, 2013), seja de acadêmicos interessados na área (PUCRS, 2010; Ferraz, 2010; Cunha, 2009; Cunha \& Gabbay, 2013), que já investigam de maneira satisfatória dos pontos de vista macro e micro.

Por isso, a presente seção não tem como objetivo repetir o senso comum teórico (Warat, 1982), mas sim, por meio de um recorte temático, investigar as causas das demandas repetitivas, sobretudo as que se referem aos contratos de adesão, tal como ocorre na maioria dos contratos de plano de saúde, mediante uma meso-análise da questão.

A singularidade de um caso jurídico é rara. Não importa o quão inusitado seja a situação, provavelmente algum Juízo do Brasil, por mais remoto que seja, já julgou um caso com elementos semelhantes, de forma que a estrutura argumentativa dessa decisão pode ser aplicada a outros casos concretos. Embora os demandantes e demandados acreditem que seus respectivos litígios sejam 'únicos'/'singulares', a realidade é que, provavelmente, a mesma temática já foi julgada milhares de vezes no Judiciário brasileiro (Cunha \& Gabbay, 2010). ${ }^{5}$

É essa a realidade da "litigiosidade em massa". Os argumentos e demandas se repetem. As petições se repetem. As decisões se repetem. Com essa mentalidade, cada sujeito do processo judicial já possui modelos/formulários para desempenharem suas respectivas atividades no script processual.

Os demandantes possuem o modelo de petição inicial com os argumentos relativos às ações mais populares, como indenização por dano moral em razão da inscrição indevida em entidades de restrição ao crédito, causas relativas ao seguro DPVAT, descumprimento de regras bancárias e as normas das relações de consumo como um todo.

Os demandados, por sua vez, tendo em vista que, em sua maioria, são grandes conglomerados ou entidades

5 Nesse sentido, Cunha \& Gabbay salientam que "existe no Brasil um mito da individualização do processo. As pessoas gostam de trabalhar sob a mitologia de que cada processo é um processo único, diferente, e não é. Qualquer um que tenha um mínimo de vivência na Justiça sabe que tudo é praticamente feito por modelo. O caso que é único é raro" (Cunha \& Gabbay, 2010, p. 136). 
estatais, também possuem modelos de defesa, utilizando as principais teses adotadas pelos Tribunais nos quais as suas respectivas defesas serão apreciadas.

Os Juízes e Desembargadores, por sua vez, também possuem decisões já prolatadas sobre casos semelhantes que são utilizadas, com as devidas adequações ao caso sub judice (Cunha \& Gabbay, 2010).

Esse conjunto de situações pode ser incluído no que é denominado "justiça de rotina", que ocupa a maior parte do trabalho exercido pelos Magistrados e seus auxiliares (Bochenek, 2013, p. 245). ${ }^{6}$

Não há uma novidade material nesses processos. ${ }^{7}$ As partes sabem disso. Enquanto, do ponto de vista da parte demandante, muitas vezes estas são incentivadas pelos próprios advogados que promovem esse tipo de prática, considerando o fenômeno da expansão da advocacia massiva contenciosa (CNJ, 2011, p. 6); do ponto de vista da parte demandada, sobretudo quando se está a se referir às relações de consumo, as desvantagens singulares que ocorrem em determinado processo, por meio de uma condenação em danos morais em valores mais elevados ou condenação mais rigorosa em razão do desrespeito aos direitos trabalhistas, são acobertadas por outras milhares de situações que ocorrem no cotidiano, mas não são

6 Nesse contexto, também é relevante destacar o papel da mídia no contencioso de massa. Com efeito, a "mídia tem uma influência, na verdade, no volume de demandas, na divulgação de teses, sem querer encontrar um culpado, sem estigmatizar qualquer um desses atores. Mas a mídia tem esse papel, a ponto de o jornal de domingo gerar um impacto muito grande no volume de casos na segunda-feira, por exemplo, que são levados aos Juizados Especiais. Ou dos jornais mais populares, com um viés bem dedicado ao direito previdenciário, colocarem questões e manchetes de, por exemplo, 'como se aposentar melhor', 'como conseguir determinado reajuste de benefício', ou uma revisão, ou mesmo veicular e difundir teses judiciais. Isso é algo realmente constante" (Cunha \& Gabbay, 2010, p. 121).

7 Beneti anota que: "A composição das lides é apenas ilusoriamente individual. Contornos principais dos casos individuais transmigram entre os autos dos processos; argumentos expostos individualmente espraiam-se a todos os processos e, ao final, fundamentos das pretensões e motivos dos julgados mesclam- se, mormente ante o fenômeno moderno da reprodução em massa de papéis via copiadoras e impressoras de computador e o envio por Internet e, entre nós, da ânsia das partes de prequestionar desde a inicial para haver acesso aos Tribunais Superiores e dos julgadores para o possível atalhe à interposição de Embargos de Declaração" (Beneti, 2009, pp. 10-11). levadas à apreciação do Poder Judiciário.

Não se está a criticar o uso de modelos de petição/ contestação/sentença/acórdão. É natural e, em alguns casos, até necessário para um mínimo de racionalização do trabalho, evitando a contraprodutividade de repetir os mesmos argumentos sobre as mesmas questões de direito. A problemática cinge-se à falta de adequação necessária ao caso concreto (Silva, 2016). Não são incomuns defesas que não rebatem a maioria dos argumentos apontados pelo autor, bem como também não são raras sentenças que não avaliam minimamente os argumentos levantados pelas partes (Sadek \& Arantes, 1994).

No caso dos planos de saúde e da maioria das relações de consumo, em linhas gerais, a situação é ainda mais complicada, tendo em vista que a vinculação entre as partes, na maioria das vezes, ocorre por meio de contratos de adesão. A concepção clássica do contrato como acordo de duas ou mais vontades, em posição de igualdade, na conformidade da ordem jurídica, destinado a estabelecer uma regulamentação de interesses entre as partes, não se adequa de maneira satisfatória à maioria dos contratos celebrados atualmente. Por sua vez, em lugar dos contratos paritários, o contrato de adesão vem ganhando cada vez mais importância, tendo em vista sua adoção em todas as relações de consumo de grande escala (Zanitelli, 2011).

Os contratos de adesão, segundo Caio Mário, são "aqueles que não resultam do livre debate entre as partes, mas provêm do fato de uma delas aceitar tacitamente as cláusulas e condições previamente estabelecidas pela outra" (Pereira, 2014, p. 50). Sendo assim, conforme salienta Orlando Gomes, "no contrato de adesão uma das partes tem que aceitar, em bloco, as cláusulas estabelecidas pela outra, aderindo uma situação contratual que encontra definida em todos os seus termos" (Gomes, 2001, p. 112).

Nesse sentido, Claudia Lima Marques pontua que:

Certo é que os fenômenos da predisposição de cláusulas ou condições gerais dos contratos e do fechamento de contratos de adesão se tornaram inerentes à sociedade industrializada moderna - em especial, nos contratos de seguro e de trans- 
porte já se observa a utilização dessas técnicas de contratação desde o século XIX. Hoje, elas dominam quase todos os setores da vida privada, é a maneira normal de concluir contratos onde há superioridade econômica ou técnica entre os contratantes, seja nos contratos das empresas com seus clientes, seja com seus fornecedores, seja com seus assalariados (Marques, 2011, p. 71).

É nesse contexto de industrialização e sociedade de consumo que a relação entre a uniformização de contratos e a massificação de conflitos ganha monta.

Hodiernamente, é possível verificar que demandas que possuem como causa de pedir o descumprimento de cláusula estipulada em contratos de adesão dominam as varas cíveis do Judiciário brasileiro. São contratos referentes a serviços de telecomunicação, planos de saúde, relações bancárias e financeiras, compras básicas de consumo, que são levados ao Judiciário em razão do desrespeito aos direitos do consumidor, dentre outras situações jurídicas que são regidas por esse tipo de contrato (Vieira, 2010).

Ora, a padronização de cláusulas e condições, por si só, não apresenta óbices aos direitos do consumidor. Trata-se de procedimento natural, uma vez que não se mostra razoável esperar que grandes fornecedores elaborem um contrato específico para cada relação de consumo realizada em seus estabelecimentos.

O problema cinge-se às cláusulas abusivas que parcela significativa dos contratos de adesão possui. Não é incomum que os fornecedores façam o cálculo do risk-reward, isto é, o cálculo que leva em consideração a propensão de determinadas divergências interpretativas serem afastadas ou mantidas no Judiciário e as vantagens que a pessoa jurídica possui com essa indeterminação, de maneira que, mesmo conhecendo a abusividade ou aceitando a ambiguidade de termos utilizados, possuam incentivos a estipular cláusulas abusivas nos seus contratos (Prudente, 2014, p. 37).

É de conhecimento das empresas que do universo de consumidores afetados por determinada cláusula abusiva, poucos irão propor ações judiciais. Parcela significativa dos consumidores não sabe que a cláu- sula é abusiva e, na maioria dos casos, os consumidores não sabem até mesmo o que seria uma cláusula abusiva (Porto \& Torres, 2013; Alves \& Xavier, 2012; Comparato, 1990; Efing, Gibran \& Blauth, 2011). ${ }^{8}$

Exemplifica-se através de uma situação hipotética. Uma instituição financeira celebrou, através de contrato de adesão com cláusula abusiva, negócios jurídicos com 5 milhões de clientes. Em razão dessa abusividade, a instituição lucra 100 milhões de reais por mês. Do universo de clientes mencionado, 10 mil consumidores verificam essa suposta abusividade e resolvem apresentar demandas ao Poder Judiciário. Desses 10 mil consumidores, 7 mil consumidores têm seus pedidos julgados procedentes. Se cada ação, ao final, tiver uma condenação média de R\$ 5 mil reais, o custo em condenações judiciais para a empresa será de R\$35 milhões. A empresa, assim, não é desistimulada; ao revés, possui incentivos para manter a cláusula considerada abusiva.

É por isso que, embora parcela da sociedade considere os altos valores obtidos em indenizações decorrentes de condenações judiciais uma espécie de "enriquecimento sem causa" da parte autora, as indenizações fixadas não devem se limitar a reparar o dano, mas também punir e dissuadir a infratora (" $p u$ nitive damages").

Sobre a importância da proteção do consumidor, Marques (2011, p. 179) anota que:

No novo direito contratual, a liberdade contratual do profissional não deve ser a única a merecer proteção jurídica, pois sua posição de poder (Machtposition) nas tratativas contratuais é clara e intrínseca aos métodos contratuais atuais, mas, sim, deve se concentrar no outro, no direito e na liberdade do outro. A liberdade do consumidor é que deve ser protegida, sua autonomia de vontade, racional e efetiva. São tempos de relações contratuais múltiplas, despersonalizadas e a du-

8 Sobre a temática de gerenciamento de grandes carteiras de processos judiciais, recomenda-se a leitura do seguinte texto: Falcone, V. F. (2014). Vantagens e desvantagens das diferentes formas de calcular ticket médio. Disponível em: <http://www.conjur. com.br/2014-out-09/victor-falcone-pros-contras-formas-calcular-ticket-medio>. Acesso em: 19 nov. 2016. 
rar no tempo e a se estender a toda uma cadeia de fornecedores de serviços e produtos. Tempos que impõem uma visão da obrigação como um processo muito mais complexo e duradouro do que uma simples prestação contratual, um dar e um fazer momentâneos entre parceiros contratuais teoricamente iguais, conhecidos e escolhidos livremente.

Ocorre que uma cláusula abusiva de um contrato de adesão não afeta apenas um consumidor ou alguns consumidores, mas sim milhares, senão milhões de cidadãos. Se o contrato é o mesmo, a abusividade, por consectário lógico, também é a mesma. Dessa maneira, a "massificação dos contratos leva à massificação dos conflitos deles decorrentes" (Magluta, 2013, p. 127).

A situação apresentada de desrespeito ao consumidor ocasionado por empresas de telecomunicação, instituições financeiras e redes de supermercados pode ser verificada, de forma clara, no Portal da Transparência das Empresas Autuadas pela Fundação Procon - SP. ${ }^{9}$ Tal portal tem como objetivo dar publicidade aos atos, bem como transparência à atividade de fiscalização do mercado de consumo realizada pelo Procon-SP, ao possibilitar que o consumidor pesquise o rol de empresas autuadas em razão de infração às normas de proteção e defesa do consumidor. Na Tabela 1, apresentada a seguir, pode-se verificar esse cenário, sendo, no entanto, relevante ressaltar que os valores apresentados se referem aos processos em tramitação na esfera administrativa e também àqueles que, após finalizados, tiveram o respectivo débito inscrito na dívida ativa do Estado de São Paulo:

\section{Tabela 1 - Empresas autuadas pelo Procon-SP}

\begin{tabular}{|l|l|}
\hline Empresas & Valor das Multas \\
\hline Vivo - Telefônica & $\mathrm{R} \$ 214.469 .862,98$ \\
\hline América Móvil (Claro, Net e Embratel) & $\mathrm{R} \$ 134.154 .278,60$ \\
\hline $\begin{array}{l}\text { Pão de Açúcar - Extra - Pontofrio.com - } \\
\text { Casasbahia.com - Casas Bahia - Ponto Frio }\end{array}$ & $\mathrm{R} \$ 71.909 .174,77$ \\
\hline
\end{tabular}

9 O Portal da Transparência das Empresas Autuadas pela Fundação Procon - SP pode ser acessado pelo seguinte endereço eletrônico: <http://sistemas.procon.sp.gov.br/transparencia/empresas_autuadas $/>$.

\begin{tabular}{|l|l|}
\hline Santander & $\mathrm{R} \$ 66.631 .902,58$ \\
\hline Itau Unibanco & $\mathrm{R} \$ 61.377 .313,43$ \\
\hline Bradesco & $\mathrm{R} \$ 57.444 .912,58$ \\
\hline Tim Celular S/A & $\mathrm{R} \$ 49.376 .287,56$ \\
\hline TAM & $\mathrm{R} \$ 47.775 .518,44$ \\
\hline BMG & $\mathrm{R} \$ 43.502 .591,33$ \\
\hline Carrefour & $\mathrm{R} \$ 34.098 .190,63$ \\
\hline
\end{tabular}

Fonte: Procon-SP (dados extraídos em novembro de 2016).

Então, o que ocorre quando esses consumidores começam a exigir seus direitos consagrados no microssistema consumerista e os fornecedores não cumprem suas obrigações legais? O cidadão, em vez de buscar os órgãos de defesa do consumidor (Procon e Delegacia de Defesa do Consumidor), procura o Judiciário para resolver o seu conflito (Terrazas, 2008; Alves, 2016).

É nesse contexto que as demandas repetitivas se apresentam. Milhões de consumidores buscando, tendo como base o princípio do acesso à justiça (Bochenek, 2013, p. 258), a prestação jurisdicional para que o seu direito seja efetivado. Tal pretensão se repete em vários casos que buscam discutir as mesmas problemáticas e questões de direito, comportando, em sua maioria, a mesma solução jurídica. Nesses casos, os fornecedores, em vez de garantirem o direito do consumidor, aceitando o que foi decidido em sede jurisdicional, buscam postergar responsabilidades, por meio de utilização de várias instâncias recursais, de maneira que o processo se torna demorado e inefetivo. O efeito dessa postergação é a entrega "tardia e, muitas vezes, ineficaz, da prestação jurisdicional, é a proliferação ainda maior dos litígios e sua consequente eternização" (Massali \& Cachapuz, 2011, p. 166).

É com essa situação em mente que o Novo Código de Processo Civil apresenta o incidente de resolução de demandas repetitivas (IRDR) em seu art. 975. É cabível a instauração do IRDR quando houver, simultaneamente, efetiva repetição de processos que contenham controvérsia sobre a mesma questão unicamente de Direito (inciso I) e risco de ofensa à isonomia e à segurança jurídica (inciso II). Tal medida tem como objetivo reduzir a quantidade de julgamentos desnecessários relativos a casos que possuem suas 
respectivas teses jurídicas já pacificadas nos respectivos Juízos. Economiza-se tempo e promovem-se vantagens para as partes do processo. 0 autor terá, caso efetivamente possua o direito material, a efetivação do que possui de direito. 0 demandado, por sua vez, não precisará ter a angústia e insegurança, por tempo prolongado, o que é comum no processo judicial. O Magistrado também não precisará repetir o julgamento quanto ao caso, podendo julgar outros processos que precisam de maior atenção por parte do Poder Judiciário (Theodoro Jr. et al., 2015).

Sendo assim, em tese, o IRDR promove diversas vantagens e benefícios para um acesso à justiça substancial, mas seria esse incidente realmente efetivo? Será efetivamente possível sua aplicação na maioria das demandas repetitivas no Judiciário que precisam dessa medida? Levando em consideração tais indagações, na próxima seção será realizada uma análise empírica-jurisprudencial, buscando realizar uma "radiografia argumentativa" e fática de determinados casos comuns em demandas repetitivas, analisando a possível aplicação do incidente nos casos de dano moral por recusa de plano de saúde.

\section{Análise empírica dos casos de dano moral e o consumidor do plano de saúde: estudo de caso do Tribunal de Justiça de Santa Catarina}

\subsection{Apontamentos metodológicos}

A análise empírica dos casos relacionados à indenização por dano moral e à possível violação de direito do consumidor por parte dos planos de saúde foi feita por meio de um estudo de caso, com dados obtidos na Justiça Estadual de Santa Catarina.

Optou-se pelo Tribunal de Justiça de Santa Catarina tendo em vista a facilidade de obtenção dos dados fornecidos pela referida Corte pelo seu endereço eletrônico institucional, bem como considerando que se trata de tribunal de médio porte, de maneira que eventuais conclusões e modelos propostos possam ser aplicados de maneira semelhante em outros tribunais.

O critério adotado para fins de recorte da pesquisa foi analisar todos os acórdãos e decisões monocráticas do Tribunal de Justiça de Santa Catarina, distribuídos ou redistribuídos por sorteio, entre primeiro de janeiro de 2015 até o último dia do mês de junho do mesmo ano, que apresentaram em suas respectivas ementas as palavras-chave: "consumidor", "plano de saúde" e "dano moral".

Frise-se que a presente pesquisa empírica não se limitou à análise das ementas dos casos que se adequam ao critério destacado; pelo contrário, o inteiro teor dos acórdãos e decisões monocráticas prolatadas no Tribunal vertente foram analisados, de maneira a permitir que fosse realizada, de forma adequada, uma "radiografia argumentativa" desta Corte. Assim, somente após a análise argumentativa será possível responder os questionamentos do estudo.

Ao todo foram analisados 58 acórdãos referentes às apelações cíveis que se adequam à delimitação do estudo. ${ }^{10}$

10 Os acórdãos dos seguintes recursos foram analisados: (1) Apelação Cível no 2014.063882-6; (2) Apelação Cível no 2012.085517-2; (3) Apelação Cível no 2014.078453-2; (4) Apelação Cível no 2012.086305-2; (5) Apelação Cível no 2014.094993-2; (6) Apelação Cível no 2014.091038-8; (7) Apelação Cível n 2013.016468-9; (8) Apelação Cível n 2014.0805025; (9) Apelação Cível no 2013.005308-7; (10) Apelação Cível no 2013.006702-4; (11) Apelação Cível no 2015.004724-8; (12) Apelação Cível no 2014.092869-1; (13) Apelação Cível n² 2012.066145-8; (14) Apelação Cível no 2012.042318-8; (15) Apelação Cível no 2013.035146-4; (16) Apelação Cível n 2014.076610-1; (17) Apelação Cível n 2014.0136511; (18) Apelação Cível n² 2014.039757-3; (19) Apelação Cível nº 2012.081345-9; (20) Apelação Cível n’ 2014.043308-2; (21) Apelação Cível n` 2014.087945-3; (22) Apelação Cível n 2014.087946-0; (23) Apelação Cível no 2014.041491-0; (24) Apelação Cível no 2014.081654-7; (25) Apelação Cível no 2012.027203-1; (26) Apelação Cível n 2014.0582213; (27) Apelação Cível n² 2013.013357-4; (28) Apelação Cível nº 2013.087323-8; (29) Apelação Cível nº 2013.087514-6; (30) Apelação Cível n² 2014.003768-4; (31) Apelação Cível no. 2014.035432-2; (32) Apelação Cível n 2014.084856-8; (33) Apelação Cível n 2014.030726-8; (34) Apelação Cível no 2015.021088-9; (35) Apelação Cível no 2015.0143423; (36) Apelação Cível no 2014.002864-7; (37) Apelação Cível nº 2015.018734-6; (38) Apelação Cível n 2014.068427-0; (39) Apelação Cível no 2014.035851-9; (40) Apelação Cível no 2014.063883-3; (41) Apelação Cível n 2013.082202-8; (42) Apelação Cível no 2015.023167-0; (43) Apelação Cível n 2014.087985-5; (44) Apelação Cível n 2013.0839236; (45) Apelação Cível n² 2014.011303-2; (46) Apelação Cível nº 2013.089832-6; (47) Apelação Cível no 2014.054744-6; (48) Apelação Cível n²013.046646-6; (49) Apelação Cível n²015.010472-0; (50) Apelação Cível no 2012.077545-8; (51) Apelação Cível no 2013.067421-4; (52) Apelação Cível no 2013.081242-9; (53) Apelação Cível n 2014.0946572; (54) Apelação Cível n 2015.026532-7; (55) Apelação Cível nº 2014.086233-1; (56) Apelação Cível no 2015.024259-4; (57) Apelação Cível n 2014.041769-3; (58) Apelação Cível n² 2015.021029-8. 
Com o objetivo de facilitar o entendimento, essa análise se dividirá em dois principais momentos. Primeiro, serão apresentados os dados objetivos do TJSC e tecidas algumas considerações sobre as informações extraídas. Em seguida, será feita a interface entre os dados obtidos e o instituto processual IRDR, tornando-se, assim, possível apresentar resultados em relação à hipótese do presente estudo.

\subsection{Dados do Tribunal de Justiça de Santa Catarina}

Primeiramente, relevante destacar a tendência do aumento de número de casos relativos à matéria de danos morais e planos de saúde. Quando comparado o primeiro semestre do quinquênio 2011-2015, pode-se observar o aumento gradual da quantidade de demandas referentes ao tema sob análise. Conforme pode ser observado no Gráfico 1, apresentado a seguir, o número de casos julgados no ano de 2015 chega a quase o triplo em relação ao ano de 2013, e mais do que o quádruplo do ano de 2011. A partir desses resultados, pode-se hipotetizar que esse acréscimo no número de demandas se deve ao aumento do número de consumidores e à maior difusão de informações quanto aos direitos que o consumidor possui em sua relação com fornecedores.

Quanto aos autores/réus, observa-se o grande impacto dos repeat players na quantidade de casos analisados. Cerca de $80 \%$, isto é, 47 casos das demandas analisadas possuem como réu ou autor a operadora de planos de saúde Unimed, abrangendo diversas cooperativas que dela fazem parte.

Gráfico 1 - Número de casos prolatados sobre a questão no primeiro semestre do ano em análise

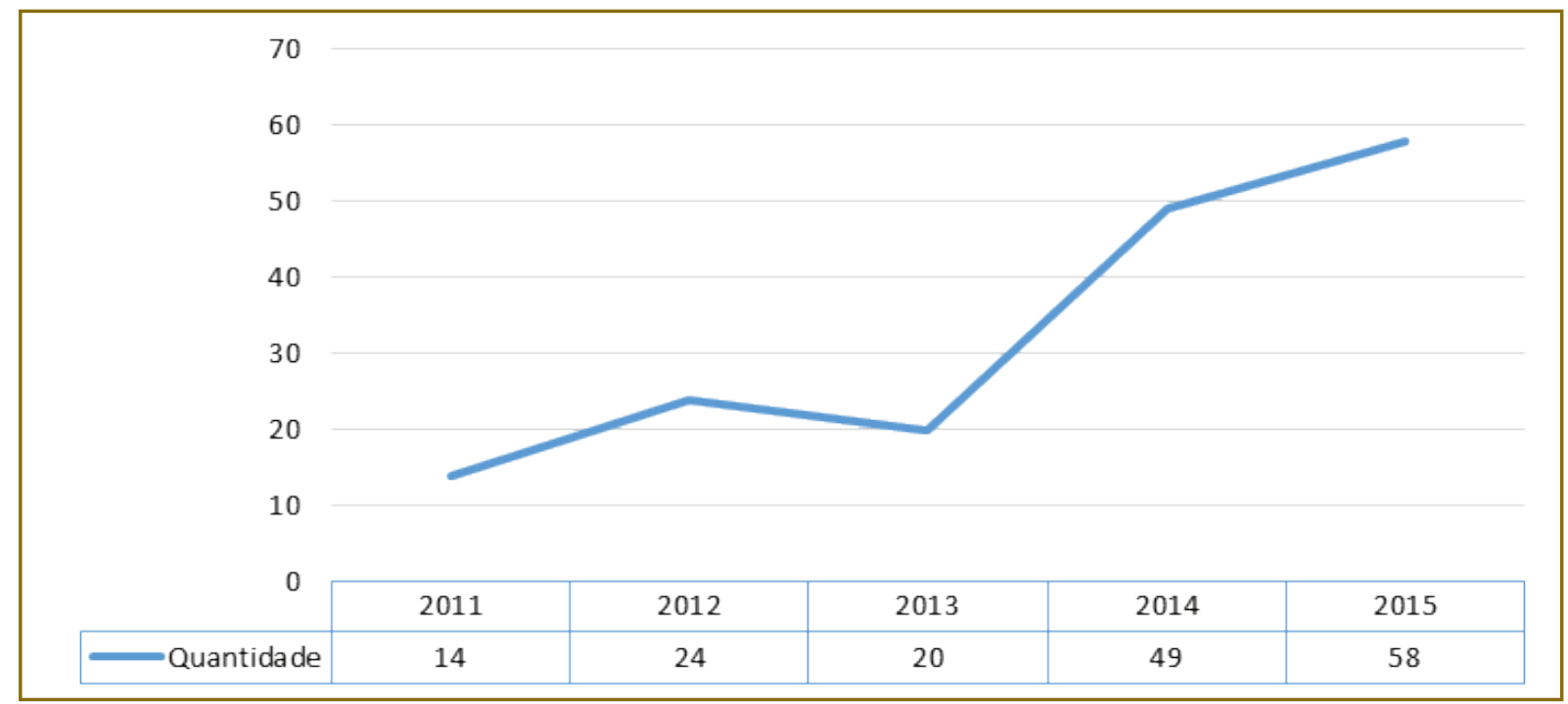

Fonte: TJSC (2015). Elaboração do autor.

Tabela 2 - Quantidade de casos por repeat players

\begin{tabular}{|l|c|}
\hline Réu/Autor & $\begin{array}{l}\text { Quantidade } \\
\text { de Casos }\end{array}$ \\
\hline $\begin{array}{l}\text { Unimed Grande Florianópolis - Cooperativa de } \\
\text { Trabalho Médico Ltda. }\end{array}$ & 18 \\
\hline $\begin{array}{l}\text { Unimed de Blumenau - Cooperativa de Traba- } \\
\text { Iho Médico Ltda. }\end{array}$ & 12 \\
\hline $\begin{array}{l}\text { Unimed Litoral - Cooperativa de Trabalho } \\
\text { Médico Ltda. }\end{array}$ & 4 \\
\hline
\end{tabular}

\begin{tabular}{|l|c|}
\hline $\begin{array}{l}\text { Unimed do Estado de Santa Catarina - Federa- } \\
\text { ção Estadual das Cooperativas Médicas }\end{array}$ & 4 \\
\hline $\begin{array}{l}\text { Unimed de Joinville - Cooperativa de Trabalho } \\
\text { Médico Ltda. }\end{array}$ & 2 \\
\hline $\begin{array}{l}\text { Unimed de Brusque - Cooperativa de Trabalho } \\
\text { Médico Ltda. }\end{array}$ & 2 \\
\hline Bradesco Saúde S/A & 2 \\
\hline
\end{tabular}




\begin{tabular}{|c|c|}
\hline Imperial Hospital de Caridade & 2 \\
\hline Agemed Saude S. A & 1 \\
\hline $\begin{array}{l}\text { Unimed de Guarapuava - Cooperativa de } \\
\text { Trabalho Médico Ltda. }\end{array}$ & 1 \\
\hline Servmed Saude Ltda. & 1 \\
\hline $\begin{array}{l}\text { Unimed de Tubarão Cooperativa de Trabalho } \\
\text { Médico da Região da Amurel Ltda }\end{array}$ & 1 \\
\hline $\begin{array}{l}\text { Fundação Assistencial dos Servidores do Mi- } \\
\text { nistério da Fazenda - Assefaz }\end{array}$ & 1 \\
\hline Sul América Companhia de Seguro Saúde S/A & 1 \\
\hline GEAP Fundação de Seguridade Social & 1 \\
\hline $\begin{array}{l}\text { Unimed RJ Cooperativa de Trabalho Médico do } \\
\text { Rio de Janeiro Ltd }\end{array}$ & 1 \\
\hline $\begin{array}{l}\text { Caixa de Assistência dos Funcionários do } \\
\text { Banco do Brasil CASSI }\end{array}$ & 1 \\
\hline $\begin{array}{l}\text { Unimed de Lages Cooperativa de Trabalho } \\
\text { Médico da Região do Planalto Serrano Ltda }\end{array}$ & 1 \\
\hline $\begin{array}{l}\text { Unimed de Criciúma Cooperativa de Trabalho } \\
\text { Médico da Região Carbonífera }\end{array}$ & 1 \\
\hline Camboriú Saúde Ltda & 1 \\
\hline $\begin{array}{l}\text { Clube Blumenauense de Caça e Tiro e Servmed } \\
\text { Saúde Ltda. }\end{array}$ & 1 \\
\hline
\end{tabular}

Nota-se, a partir da análise da Tabela 2, que a maioria dos casos possui a Unimed como integrante da triangulação processual. Esse indicador pode ser atribuído: (a) à Unimed possuir um maior número de associados em relação às outras operadoras de plano de saúde, de maneira que seria natural que uma empresa com muitos consumidores também possua um maior número de processos judiciais; (b) às outras operadoras de plano de saúde respeitarem a decisão da primeira instância e não recorrerem; (c) à Unimed possuir uma tese jurídica específica que objetiva ser aceita nos tribunais do Brasil, de maneira que não busca se adaptar aos entendimentos das cortes locais.

Há, sobretudo, um grande pleiteamento recursal no que se refere ao dano moral. Os planos de saúde buscam afastá-lo ou, pelo menos, mitigá-lo, enquanto os consumidores buscam majorá-los.

Dos 58 processos analisados, 17 tiveram seus valores do dano moral majorados e 11 tiveram seus valores reduzidos, com 30 valores mantidos. Quanto à fixação do valor do dano moral, destaca-se que a média, contanto que o consumidor não possua doença grave e não seja idoso, é de cerca de R\$ 10.000,00.

Fonte: TJSC (2015). Elaboração do autor.

Gráfico 2 - Fixação do dano moral (1 ${ }^{a}$ Instância vs. $2^{a}$ Instância)

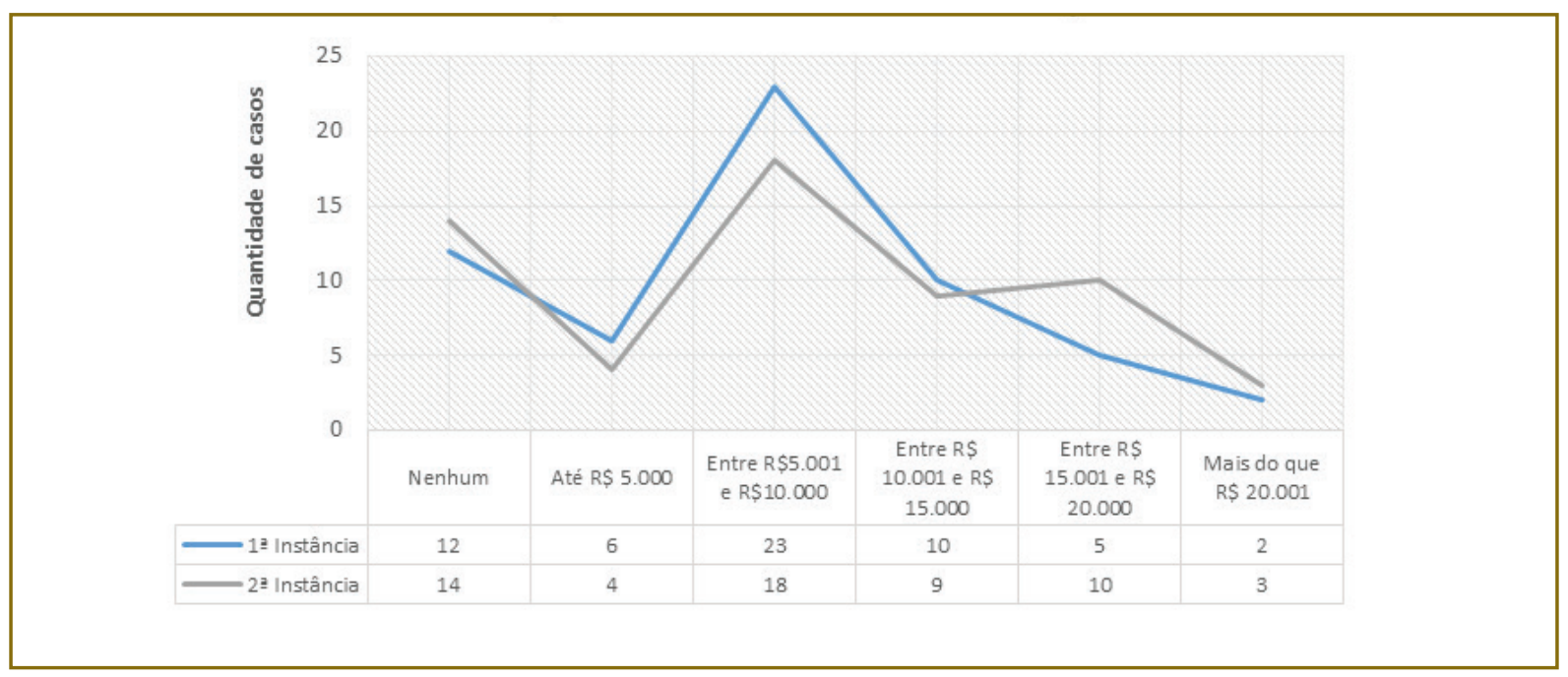

Fonte: TJSC (2015). Elaboração do autor. 
Observa-se, pela leitura dos acórdãos, que todos os votos salientam que o mero inadimplemento contratual não gera efeitos danosos anímicos, de forma que o dano deve ir além do mero aborrecimento, atingindo os bens essenciais do ser humano, como a saúde e a vida, cuja violação é comum em demandas judiciais quanto à recusa de atendimento por planos de saúde. Ademais, ressaltam que o dano moral, por evidente, deve ser proporcional e adequado ao dano (utilizam os princípios da proporcionalidade e razoabilidade), cumprindo o papel pedagógico e inibidor da indenização. As majorações, em sua maioria, ocorreram em casos que envolvem pessoas de baixa renda, idosos, indivíduos com doenças graves que precisam de atendimento de emergência, bem como nos casos que o espaço de tempo entre requerimento e a realização do procedimento se mostrou longo e desarrazoado.

Em casos que, embora tenha ocorrido a recusa pelos planos de saúde, os jurisdicionados tenham obtido o atendimento solicitado, como, por exemplo, por ordem judicial, a tendência observada foi o afastamento do pedido de dano moral, tendo em vista que nesses casos teria ocorrido mero aborrecimento, uma vez que não houve prejuízo à saúde.

Quanto à fixação do valor do dano moral, relevante destacar três aspectos utilizados pelo Gabinete do Des. Raulino Jacó Brüning para reduzir a subjetividade e verificar a proporcionalidade do valor arbitrado: (a) econômicos: verificam-se as condições econômicas do autor e do réu, que na maioria dos casos são sociedades jurídicas próprias, entidades com fins filantrópicos, as quais prestam serviços médicos/ hospitalares, que possuem grande capacidade econômica; (b) temporais: o tempo decorrido até que o consumidor tenha obtido êxito no seu requerimento; (c) responsabilidade: se a conduta em análise seria reprovável e atribuível à negligência e grave falha na prestação de serviços e operacionalização de dados pela demandada.

No que se refere aos argumentos, sejam principais ou secundários, utilizados pelos planos de saúde, pode-se observar uma certa homogeneidade no sentido de se adotar argumentos que não se adequam de maneira satisfatória ao Código de Defesa de Consu- midor, o que é esperado, uma vez que, como qualquer empresa, a busca pela redução de custos é natural. Tratam-se de argumentos que são facilmente refutáveis quando adotados os princípios básicos do microssistema consumerista e a interpretação mais favorável do consumidor, conforme pode ser verificado no quadro abaixo: ${ }^{11}$

\section{Quadro 1 - Fundamentação dos planos de saúde}

\begin{tabular}{l} 
Não há ilicitude na negativa de atendimento em hospital não cre- \\
denciado e expressamente excluído de sua rede de atendimento. \\
\hline O rol da Resolução no $211 / 2010$ da ANS é exaustivo e, por isso, \\
ao recusarem procedimentos que não estão expressos no \\
contrato de adesão, não estão praticando ato ilícito. \\
\hline Cobertura contratual ilimitada não é obrigatória e que, se \\
assim fosse, haveria um desequilíbrio na relação contratual. \\
Os planos de saúde suscitam, preliminarmente, a ilegitimidade \\
passiva ad causam, afirmando que não possuem qualquer \\
relação com o possível direito material invocado pelo autor, \\
impugnando qualquer responsabilidade solidária decorrente \\
dos atos praticados pelos médicos cooperados. Atribuem ex- \\
clusivamente ao médico a responsabilidade pela sua conduta, \\
pleiteando a sua exclusão do polo passivo da lide.
\end{tabular}

Sustentam que, dos fatos narrados pela demandante, não há danos morais indenizáveis, uma vez que a negativa em autorizar os procedimentos não causou nenhum prejuízo à sua saúde.

Afirmam que há ilegitimidade ativa dos herdeiros em ações de dano moral, uma vez que, de acordo com este entendimento, seria uma ação personalíssima.

Alegam cerceamento de defesa quando o Juiz indefere medidas que são consideradas diligências inúteis ou meramente protelatórias, como, por exemplo, indeferimento de depoimento pessoal.

O fornecimento de próteses, órteses e seus acessórios estão expressamente excluídos da cobertura contratual firmada com a autora, nem constam no rol de procedimentos instituído pela ANS - Agência Nacional de Saúde Suplementar. Por isso, a recusa desse fornecimento é justificada.

De forma geral, as cláusulas foram redigidas em consonância com o Código de Defesa do Consumidor, motivo pelo qual não há que se falar em abusividade ou contradição entre os dispositivos.

Não há que se falar em aplicação da Lei n. 9.656/98, que dispõe sobre os planos e seguros privados de assistência à saúde, e da Lei n. 10.741/03, que dispõe sobre o Estatuto do Idoso, aos contratos firmados antes da sua publicação, sob pena de ofensa ao ato jurídico perfeito.

11 Salienta-se que alguns argumentos, tendo em vista a precisão da fundamentação utilizada, foram transcritos de forma literal para o quadro em destaque, visando apresentar a argumentação de maneira mais autêntica possível. 
Não há qualquer irregularidade no reajuste das mensalidades por faixa etária, uma vez que, além de não ocorrido unilateralmente, os planos de saúde estão resguardados contratualmente.

Alega-se que caso o tratamento indicado pelo médico possua caráter experimental e não reconhecido/registrado pela ANVISA, o plano de saúde não possui obrigação de oferecer o tratamento solicitado. $O$ caráter experimental abrange os tratamentos que ainda estão sujeitos a observações científicas.

Fonte: TJSC (2015). Elaboração do autor.

Nota-se que tais argumentos, em sua maioria, restringem-se a discutir questões de direito, de forma que as questões de fato são pouco abordadas. No caso, limitam-se a afirmar que certa moléstia não se adequa às exigências de determinada resolução; a afirmar que o contrato foi firmado de maneira adequada, não sendo possível alegar abusividade, buscando fundamentos no clássico princípio do pacta sunt servanda e no exercício regular do direito; dentre outros.

É demonstrativa dessa insuficiente discussão quanto às questões de fato a Apelação Cível n²014.0684270 , que possui como relator o Des. Gilberto Gomes de Oliveira. No caso vertente, o Relator critica a utilização de modelo de peças que tratam de matéria diversa da debatida, utilizando-se de meras alegações genéricas, violando o princípio da dialeticidade. Nesse sentido, salienta que tem notado que:

[...] nos recursos de motivação livre, a crescente evolução de uma característica que muito me preocupa, a saber, a completa ausência de interesse, por parte do recorrente, de expor os motivos da sua insatisfação, a ponto de se copiar, com as facilidades da modernidade, uma contestação inteira denominando-a, apenas, de recurso de apelação, quando não se utiliza modelos aleatórios, sem nem sequer adequá-los ao caso concreto (TJSC, 2015).

No que se refere aos argumentos, sejam principais ou secundários, pelos Desembargadores do Tribunal de Justiça de Santa Catarina para solucionar os conflitos concernentes a pedidos de dano moral em ações que envolvem planos de saúde, pode-se notar que a Corte está atualizada quanto aos preceitos e princípios do Código de Defesa do Consumidor, adotando posições favoráveis ao consumidor, sobretudo com base nos arts. 46, 47 e 51, e no princípio da boa-fé, que deve ser observado em toda relação jurídica. A fundamentação utilizada pode ser verificada no Quadro 2 abaixo: ${ }^{12}$

\section{Quadro 2 - Fundamentação dos acórdãos}

O rol da Resolução n 211/2010 da ANS é meramente exemplificativo, de forma que os procedimentos listados pela ANS se caracterizam como um patamar mínimo a ser disponibilizado pelos planos de saúde em âmbito nacional, e não como um rol exaustivo de procedimentos a ser disponibilizado pelos planos. Por isso, os planos de saúde devem disponibilizar procedimento não elencado na mencionada Resolução da ANS quando imprescindível para o tratamento do usuário.

Teoria finalista (subjetiva). O Código de Defesa do Consumidor é aplicável aos contratos de plano de saúde, nos termos da Súmula 469 do Supremo Tribunal Federal.

Quanto ao dano moral, seguem o entendimento de que é prescindível a prova material da dor moral, uma vez que esta se presume. Deve-se provar, sim, a situação fática passível de indenização por dano moral, de forma que a "dor" em si será observada a partir da situação apresentada.

Caráter pedagógico e inibidor do dano moral. Afirma-se que, em que pese o mero inadimplemento contratual não gerar efeitos danosos anímicos ipso facto, na maioria dos casos, por se tratar de avença em que se discute bens de extrema importância, a saúde e a vida, é possível aferir-se de plano a ocorrência do abalo moral (dano in re ipsa).

O arbitramento da indenização pelo Magistrado levará em consideração os critérios de razoabilidade e proporcionalidade, além de analisar as peculiaridades do caso concreto.

Natureza experimental de tratamento. Nos casos que os planos de saúde possuem cobertura para o tratamento da doença que acomete o(a) autor(a) e o médico indica tratamento experimental e não reconhecido/registrado pela ANVISA, é necessário a comprovação da necessidade do tratamento experimental em Juízo.

A oposição de resistência injustificada ao cumprimento dos deveres assumidos pelo prestador de serviços perante o consumidor é fato antijurídico passível de gerar dano moral, sobretudo quando envolve a saúde do usuário. A negativa de atendimento a cliente internado após acidente grave e necessitando de encaminhamento emergencial à intervenção cirúrgica é fato gerador de elevado grau de angústia em pessoa já fragilizada. A decepção, aliada ao risco imposto à saúde e o tratamento pouco digno conferido ao consumidor são fatores que, no conjunto, configuram o dano moral indenizável.

12 Salienta-se que alguns argumentos, tendo em vista a precisão da fundamentação utilizada, foram transcritos de forma literal para o quadro em destaque, visando apresentar a argumentação de maneira mais autêntica possível, sem qualquer intenção de infringir os direitos autorais dos seus respectivos autores. 
Legitimidade ativa dos sucessores em casos de dano moral. Adota-se o entendimento de que a legitimidade dos recorridos refere-se, tão somente, à substituição processual e não à iniciativa de propositura da ação, uma vez que, se a parte falecida, autora original da ação, tiver direito de receber a compensação pelos danos morais sofridos em decorrência da recusa em reembolsar os gastos com o tratamento, este valor integrará o seu patrimônio, uma vez transmissível aos seus sucessores em caso de morte.

Não abusividade de cláusula de reembolso. É lícita cláusula contratual que preveja a possibilidade de reembolso das despesas com atendimento à saúde em caráter emergencial ou de urgência, executado por profissionais ou prestadores de serviço não cooperados. A cobertura dos serviços prestados por profissionais não credenciados fica limitada aos valores da tabela do plano contratado, de forma que eventuais valores excedentes deverão ser custeados pelo próprio contratante.

Havendo disposição genérica no contrato para implantação de próteses cirúrgicas, apresenta-se injustificada a negativa da operadora de plano de saúde em proporcionar à paciente prótese importada para a realização de intervenção cirúrgica quando o implante for necessário para o tratamento de sua patologia. Assim, a espécie "prótese importada" está contida no gênero "próteses".

O plano de saúde deve limitar-se a estabelecer a cobertura das patologias, e não os materiais a serem empregados no tratamento de cada uma delas.

Quanto à preliminar cerceamento de defesa, argumento utilizado pelos planos de saúde, na maioria dos casos não é acolhido porque, diante do princípio do livre convencimento motivado do juiz, compete ao magistrado, responsável pela causa, determinar as provas que entenda necessárias à instrução do processo, pelo que deve indeferir as diligências inúteis ou meramente protelatórias. Quando a questão controversa é apenas de fato e estando suficientemente demonstrada nos autos por meio da prova documental, a conduta do Magistrado a quo de julgar antecipadamente a lide, tendo em vista que constatou no processo que o conjunto probatório era suficiente para apreciação da causa, é justificada a negativa de diligências.

Se o procedimento cirúrgico é, em princípio, abrangido por cláusula genérica inserta na listagem de serviços oferecidos e não há previsão específica de exclusão, reconhece-se o direito à cobertura. A recusa somente seria lícita se tal exclusão houvesse sido prévia e expressamente informada ao consumidor quando da adesão ao plano contratado.

O procedimento cirúrgico deve ser realizado por questões técnicas pertinentes e só podem ser devidamente avaliadas pelo médico competente, e não de maneira apriorística pela operadora de plano de saúde. Tratam-se de prerrogativas inafastáveis do profissional de saúde, nos termos do Código de Ética Médica.
Ausência de prova relativa à negativa do plano de saúde, por meio de requerimento administrativo, inviabiliza a indenização por danos morais, diante da ausência do ato ilícito.

Descabe à operadora do plano de saúde visar apenas a um interesse meramente econômico, em detrimento de um bem maior: o direito à saúde e à vida.

Se o plano de saúde cobre determinado procedimento médico, não há como considerar a legalidade de exclusão do fornecimento de materiais necessários ao procedimento cirúrgico, pois cabe ao médico avaliar qual procedimento é mais indicado ao problema de saúde enfrentado pelo paciente. A escolha dos materiais a serem empregados na execução de cirurgia deve obedecer a critérios médicos, visando a redução de riscos e a melhor forma de preservar a saúde do paciente.

Não há impedimento para aplicação dos ditames da Lei n. 9.656/98 aos contratos firmados em data pretérita à sua vigência, porquanto são de renovação anual e sua adequação à nova ordem jurídica é automática. A Lei de Planos de Saúde, em que pese não retroagir, tem aplicação imediata para regular os efeitos presentes e futuros do negócio jurídico pretérito celebrado entre as partes.

Não é permitido à operadora do plano de saúde assegurar a realização de exames, diagnósticos e terapias relacionados a diversas áreas de especialidade, mas excluir, por outro lado, os tratamentos prescritos ou o fornecimento de materiais e próteses imprescindíveis ao eficaz resultado do procedimento e à própria convalescença do enfermo. Viola-se, dessa forma, a boa-fé e o contrato deve ser interpretado de forma mais favorável ao consumidor (art. 47, CDC).

Se o plano do autor é de abrangência nacional, por evidente, tem como o limite o território brasileiro. Restringir a realização de procedimentos em determinados hospitais, também integrantes do sistema de saúde em outros Estados da Federação, apresenta-se como abusivo. Ademais, é dever da demandada, pelo menos, indicar outro local credenciado à sua rede, não podendo se limitar a restringir os hospitais credenciados.

O silêncio da demandada até o final do dia seguinte ao requerimento (último útil precedente à data do exame), equipara-se, em última análise, à própria recusa de cobertura, igualmente ilegítima na hipótese.

Em tema de planos de saúde, o contrato é concebido para atender os custos pertinentes a tratamento de determinadas doenças, deve ele dispor apenas sobre quais as patologias cobertas e não sobre os tipos de tratamentos cabíveis a cada uma delas. Do contrário, seria aceitar que a empresa que gerencia o plano de saúde decidisse no lugar do médico qual o tratamento mais indicado. 
Teoria da aparência. Cooperativas que pertencem ao mesmo conglomerado empresarial. Adota-se o entendimento de que não se pode exigir do consumidor, presumidamente hipossuficiente, conhecimento técnico para diferenciar cada unidade desmembrada da cooperativa, cujos integrantes do pool empresarial facilmente se confundem, uma vez que ele pode firmar contrato com determinada cooperativa, e outro pode vir a autorizar ou negar cobertura para realização de exames, tratamentos e cirurgias, como ocorreu no caso dos autos.

De acordo com o art. 35 da Lei 9.656/98, aos consumidores que já possuíam plano de saúde anterior à referida lei ficou assegurada a possibilidade de se amoldarem às novas regras. É dever da seguradora, segundo a Agência Nacional de Saúde, oferecer a opção, sob pena de violar o direito de informação previsto no art. $6^{\circ}$, inciso III, do Código de Defesa do Consumidor. Assim, para que seja reconhecida a inaplicabilidade da Lei 9.656/1998 é necessária a comprovação de que foi ofertada ao segurado a migração, ônus que, obviamente, incumbe à operadora do plano de saúde, diante da impossibilidade da produção de prova negativa pelo consumidor, aliada à possibilidade de inversão do ônus probatório prevista no artigo $6^{\circ}$, inciso VIII, do CDC.

Fonte: TJSC (2015). Elaboração do autor.

A partir da observação desses argumentos, vislumbra-se que, em sua maioria, são soluções referentes a questões de direitos que podem ser aplicadas a outras demandas repetitivas. A título de exemplo, a ratio decidendi é que o plano de saúde deve limitar-se a estabelecer a cobertura das patologias, e não os materiais a serem empregados no tratamento de cada uma delas, pode ser aplicada em uma variedade de casos semelhantes, sem que o devido processo legal e o contraditório substancial sejam obnubilados.

As questões de fato, por sua vez, são citadas quando se está a se referir ao dano moral e à fixação da indenização. No processo de arbitramento, embora já possuam trechos padrões referentes à subjetividade do dano moral e à necessidade de passar do mero aborrecimento, levam em consideração outros fatores, conforme citado alhures, tal como os aspectos econômicos, temporais e a responsabilidade do operador do plano de saúde.

\subsection{Sobre a possibilidade da aplicação dos incidentes de demandas repetitivas nos casos em análise}

Então, a partir do cenário de "demanda de massas" e da fundamentação analisada nos casos em tela, volta-se à pergunta inicial do estudo: o incidente de resolução de demandas repetitivas poderá ser aplicado em casos de apelação cível referente a obrigações de fazer, com indenização de danos morais relativos ao inadimplemento por parte das operadoras dos planos de saúde?

A resposta é positiva. No entanto, cabe ressaltar algumas peculiaridades que podem fazer com que tal instrumento processual não tenha a eficácia desejada, uma vez que não há sentido possibilitar a aplicação do instituto processual, mas não analisar o modo como será aplicado.

Primeiro, lembra-se que o art. 976, do Código de Processo Civil de 2015, afirma ser cabível a instauração do IRDR, quando estiverem presentes, simultaneamente, dois requisitos: efetiva repetição de processos que contenham controvérsia sobre a mesma questão unicamente de Direito (inciso I) e risco de ofensa à isonomia e à segurança jurídica (inciso II).

O segundo requisito não causa polêmica, uma vez que é justamente nas demandas repetitivas que são observadas de forma clara as violações à isonomia e à segurança jurídica, abrindo azo para a "jurisprudência lotérica". Nesses casos, "se um órgão jurisdicional julga de um jeito e outro de outro, instaura-se uma atmosfera de incerteza, com a consequência de retirar a credibilidade social da administração da justiça" (Cambi, 2001). Em termos práticos, a realização do direito material do pleiteante (Bedaque, 2011), em tais casos, depende do Juízo para o qual o caso será distribuído, uma vez que não é incomum a criação de uma própria "jurisprudência” de cada Juízo que, por vezes, são contrários ao posicionamento do Tribunal de Justiça ou Tribunal Regional Federal do qual integra (Leal, 2010).

A verdadeira discussão quanto à eficácia da norma cinge-se ao primeiro requisito, que se refere à necessidade de efetiva repetição de processos que contenham controvérsia sobre a mesma questão unicamente de Direito. A problemática repousa na expressão utilizada na última parte do inciso questão unicamente de Direito -, uma vez que nos casos de relação de consumo não é incomum o pedido de danos morais, que exige a análise de questões de fato. 
As questões relativas ao direito, como, por exemplo, permitir a aplicação da teoria da aparência, no caso de cooperativas que pertencem ao mesmo conglomerado empresarial, ou, declarar que a resolução $n^{\circ}$ 211/2010 da ANS possui um rol meramente exemplificativo, poderão ser abordadas em IRDR; mas e o pedido de dano moral que frequentemente é utilizado nessas situações? Em teoria, continuará sendo (re) analisado em segunda instância.

Assim, o ponto central da discussão é que é preciso ter certa cautela ao afirmar que o IRDR "solucionará" o problema das demandas repetitivas, evitando que os julgadores tenham que decidir as mesmas demandas que exigem as mesmas soluções diversas vezes, de forma que a carga processual, quanto essas questões, diminuirá. Ora, é necessário lembrar de questões de fato, como o dano moral, que na sociedade da industrialização do dano moral vem cada vez mais crescendo, impede até certo ponto essa expectativa.

A título de exemplo, um Juiz de Santa Catarina observa que o plano de saúde está a recusar/limitar determinado material ou procedimento recomendado por médico do autor, idoso que possui doença cardíaca e respiratória, de forma que o autor apresenta uma ação pedindo para que o operador do plano seja obrigado a fornecer o material solicitado (obrigação de fazer) e seja indenizado pelos danos morais que a recusa ocasionou, sobretudo nesse momento de angústia.

No caso vertente, se, por meio do IRDR, o Tribunal estabelecesse o entendimento de que o "plano de saúde deve limitar-se a estabelecer a cobertura das patologias, e não os materiais a serem empregados no tratamento de cada uma delas", em tese, o Juiz poderá aplicar esse entendimento e solucionar o conflito do qual está diante, fixando dano moral em $\mathrm{R} \$ 10.000,00$, tendo em vista que a situação ultrapassou o mero aborrecimento.

Ocorre que os réus, as grandes operadoras de plano de saúde, possuem uma tendência de continuar interpondo recursos para diminuir os valores de dano moral arbitrado. Até podem não questionar a solução apresentada em IRDR, mas continuarão, com base nos princípios da proporcionalidade e razoabilidade, afirmando que o valor se apresenta desarrazoado e merece ser reduzido para evitar o enriquecimento ilícito do autor.

É nesse contexto que se apresenta necessário, além da promoção do IRDR, um incentivo ao diálogo com as instituições competentes (diálogos institucionais) para ilidir causas repetitivas, evitando a litigiosidade que pode ser vista hodiernamente. No estudo de caso apresentado, por exemplo, seria fundamental o diálogo com a Unimed e suas cooperativas, uma vez que mais de $80 \%$ dos casos analisados a possuem como ré ou autora, buscando averiguar os motivos dessa situação e se seria possível sua solução de modo mais amigável.

Relevante ressaltar que, durante a elaboração da pesquisa, foi editado o primeiro IRDR da Câmara de Direito Público do Tribunal de Justiça de Santa Catarina, o Incidente de Resolução de Demandas Repetitivas n 0302355-11.2014.8.24.0054/50000, de Rio do Sul, possuindo como relator o Des. Ronei Danielli. ${ }^{13}$

Nesse IRDR, foram estabelecidas duas teses jurídicas.

A primeira é que, para a concessão judicial de remédio ou tratamento constante do rol do SUS, devem ser conjugados os seguintes requisitos: $(a)$ a necessidade do fármaco perseguido e adequação à enfermidade apresentada, atestada por médico; $(b)$ a demonstração, por qualquer modo, de impossibilidade ou empecilho à obtenção pela via administrativa.

A segunda tese firmada pela Câmara de Direito Público do TJSC é que, para a concessão judicial de fármaco ou procedimento não padronizado pelo SUS, são requisitos imprescindíveis: $(a)$ a efetiva demonstração de hipossuficiência financeira; (b) ausência de política pública destinada à enfermidade em questão ou sua ineficiência, somada à prova da necessidade do fármaco buscado por todos os meios, inclusive mediante perícia médica; (c) nas demandas voltadas aos cuidados elementares à saúde e à vida, ligando-se à noção de dignidade humana (mínimo existencial), dispensam-se outras digressões; $(d)$ nas demandas

130 teor do acórdão pode ser verificado no seguinte endereço eletrônico: <http://d2f17dr7ourrh3.cloudfront.net/wp-content/ uploads/2016/11/IRDR-medicamentos.pdf>. 
claramente voltadas à concretização do máximo desejável, faz-se necessária a aplicação da metodologia da ponderação dos valores jusfundamentais, sopesando-se eventual colisão de princípios antagônicos (proporcionalidade em sentido estrito) e circunstâncias fáticas do caso concreto (necessidade e adequação), além da cláusula da reserva do possível.

Observa-se que o IRDR sob análise se adequa à proposta do Código de Processo Civil. Busca-se delimitar requisitos para a concessão judicial de remédio ou tratamento constante do rol do SUS (primeira tese) e dos que não constam no rol do Sistema Único de Saúde (segunda tese), de modo que, a título de exemplo, se um magistrado exigir algum requisito (ou não exigir algum requisito do IRDR) que não está estabelecido no incidente, a parte prejudicada poderá propor reclamação, com fundamento no art. 988, IV e 985, § $1^{\circ}$, do CPC, no TJSC, buscando garantir a observância de acórdão proferido em julgamento de incidente de resolução de demandas repetitivas.

\section{Conclusão}

Ante o exposto, conforme restou demonstrado no presente estudo, é possível a aplicação do incidente de resolução de demandas em casos de apelação cível referente a obrigações de fazer, com indenização de danos morais relativos ao inadimplemento de planos de saúde, visando garantir uma maior isonomia e segurança jurídica, sobremaneira quando se está a tratar de consumidores que raramente necessitam de atendimento médico, mas quando precisam, ficam diante de recusas das operadores de plano de saúde, causando angústia e, como um todo, dano moral.

No entanto, faz-se mister ressaltar que tão somente a aplicação dos incidentes não é suficiente para apresentar uma "solução" para o problema enfrentado pelo Poder Judiciário brasileiro. Sendo, nesse contexto, necessário um incentivo ao diálogo com as instituições competentes (diálogos institucionais) para ilidir causas repetitivas, evitando a explosão de litigiosidade que pode ser observada hodiernamente.

Isso ocorre porque, embora o IRDR possa ser aplicado em diversas situações de demandas repetitivas, tem sua atuação limitada às questões unicamente de direi- to, de maneira que os planos de saúde ainda podem apresentar elevados números de recursos sobre questões de fato, tal como o valor fixado de danos morais.

HIIIIIIIIIIIIIIIIIIIIIIIIIIIIIIIII 


\section{Referências}

Alves, F. G. \& Xavier, Y. M. D. A. (2012). Hermenêutica contemporânea dos direitos fundamentais. Revista Direito e Liberdade, 14(1), pp. 123-144.

Alves, F. G. P. (2016). Ações de saúde contra o poder público: ensaio de um roteiro decisório. Revista Direito e Liberdade, 18(3), pp. 79-127.

Bedaque, J. R. S. (2011). Direito e Processo: influência do direito material sobre o processo. 6 . ed. São Paulo: Malheiros.

Beneti, S. A. B. (2009). Assunção de competência e fast-track recursal. RePro, 34 (171), pp. 9-23.

Bochenek, A. C. (2013). A litigiosidade cível e o acesso à Justiça Federal brasileira. Série Monografias do CEJ, v. 15.

Cambi, E. (2001). Jurisprudência Lotérica. Revista dos Tribunais, 786 (379), pp. 108-128.

CJF. Conselho da Justiça Federal. (2016). Quadro de juízes(as) federais e substitutos. Disponível em: $<$ http://daleth.cjf.jus.br/atlas/Internet/QUADRODEJUIZESSJ.htm>. Acesso em 18 nov. 2016.

(2013). Seminário demandas repetitivas na Justiça Federal: possíveis soluções e processuais e gerenciais. Brasília: Conselho da Justiça Federal, Centro de Estudos Judiciários.

CNJ. Conselho Nacional de Justiça. (2016). Justiça em Números 2016: ano-base 2015. Brasília: CNJ.

(2011). Demandas Repetitivas e a morosidade na Justiça Cível Brasileira. Brasília: Departamento de Pesquisa Judiciárias.

. (2011). Estudo comparado sobre Recursos, Litigiosidade e Produtividade: a prestação jurisdicional no contexto internacional. Brasília: Departamento de Pesquisas Judiciárias.

Comparato, F. K. (1990). A proteção ao consumidor na Constituição Brasileira de 1988. Revista de Direito Mercantil, Industrial, Econômico e Financeiro, 39 (80), pp. 66-75.

Cunha, L. J. C. (2009). As causas repetitivas e a necessidade de um regime que lhes seja próprio. Revista da Faculdade de Direito do Sul de Minas, 25 (2) pp. 236-268.

Cunha, L. G. \& Gabbay, D. M. (2010). Diagnóstico sobre as causas de aumento das demandas judiciais cíveis, mapeamento das demandas repetitivas e propositura de soluções pré-processuais, processuais e gerenciais à morosidade da Justiça. Brasília:
Conselho Nacional de Justiça.

Cunha, L. \& Gabbay, D. Morosidade e demandas repetitivas. In: Cunha, A. S. \& Silva, P. E. A. (orgs.) (2013). Pesquisa empírica em Direito. Rio de Janeiro: Ipea.

Efing, A. C.; Gibran, F. M. \& Blauth, F. N. L. (2011). A proteção jurídica do consumidor enquanto direito fundamental e sua efetividade diante de empecilhos jurisprudenciais: o enunciado 381 do STJ. Direitos Fundamentais \& Justiça, 5(17), pp. 207226.

Ferraz, L. S. (2010). Acesso à justiça: uma análise dos Juizados Especiais Cíveis no Brasil. Rio de Janeiro: Editora FGV.

Gomes, O. (2001). Contratos. 24. ed. Rio de Janeiro: Forense.

Leal, F. A. R. (2010). Todos os casos jurídicos são difíceis? Sobre as relações entre efetividade, estabilidade e teorias da decisão constitucional. Revista de Direito do Estado, 16, pp. 87-116.

Magluta, N. C. M. (2013). A Massificação dos Conflitos de Consumo e o Sistema dos Juizados Especiais Cíveis como Instrumento de Pacificação. Série Aperfeiçoamento de Magistrados. Rio de Janeiro: EMERJ.

Marques, C. L. (2011). Contratos no código de defesa do consumidor: o novo regime das relações contratuais, 6. ed. rev., atual. e ampl. São Paulo: Revista dos Tribunais.

Massali, W. E. G. \& Cachapuz, R. R. (2011). Arbitragem: uma saída liberal à crise do judiciário. Scientia iuris, 15(2), pp. 165-183.

Nunes, D. \& Bahia, A. M. F. (2015). Precedentes no CPC-2015: por uma Compreensão Constitucionalmente Adequada do seu uso no Brasil. Revista do Ministério Público do Rio de Janeiro, 57, pp. 17-52.

Pereira, C. M. S. (2014). Instituições de direito civil Contratos. v. 3. Rio de Janeiro: Forense.

PUCRS. (2010). Demandas judiciais e morosidade da justiça civil: relatório final. Porto Alegre: PUCRS. Disponivel em: <https://issuu.com/cnj_oficial/ docs/rel_ttorio_sobre_as_demandas_judici >. Acesso em: 16 dez. 2016.

Porto, A. A. C. \& Torres, C. M. (2013). A importância da percepção holística do consumidor como suporte de uma sociedade perdurável. Revista Direito e Liberdade, 15(2), pp. 63-92.

Procon. (2016). Portal da Transparência das Empresas 
Autuadas pela Fundação Procon - SP. Disponível em: <http://sistemas.procon.sp.gov.br/transparencia/empresas_autuadas>. Acesso em: 19 nov. 2016.

Prudente, R. R. O.S. (2014). Motivação das demandas judiciais repetitivas em Goiás. Dissertação (Mestrado em Direito) - Programa de Pós-Graduação Stricto Sensu em Direito Constitucional: Constituição e Sociedade, Instituto Brasiliense de Direito Público (IDP).

Sadek, M. T. A (Org.). (2016). Magistrados: uma imagem em movimento. São Paulo: Editora FGV.

(2009). Justiça em números: novos ângulos.

São Paulo: Associação dos Magistrados Brasileiros.

Sadek, M. T. \& Arantes, R. B. (1994). A crise do Judiciário e a visão dos juízes. Revista USP, (21), pp. 34-45.

Silva, L. M. (2016). Do estado liberal ao modelo republicano de estado: o direito constitucional processual de defesa. Revista da Faculdade de Direito do Sul de Minas, 32(1), pp. 137-162.

Terrazas, F. V. (2008). O poder judiciário como voz institucional dos pobres: o caso das demandas judiciais por medicamentos (Dissertação de Mestrado). São Paulo: Faculdade de Direito da Universidade de São Paulo.

Theodoro Júnior, H.; Nunes, D.; Franco, A. M. \& Pedron, F. Q. (2015). Novo CPC: fundamentos e sistematização. Rio de Janeiro: Forense.

TJSC. Tribunal de Justiça de Santa Catarina. (2015). Jurisprudência Catarinense. Disponível em: $<$ <ttp://busca.tjsc.jus.br/jurisprudencia/>. Acesso em: 25 jul. 2015.

Vieira, N. D. (2010). Interpretação constitucional dos riscos de desenvolvimento no direito do consumidor brasileiro: visões jurídicas nacional e internacional. Rev. Direito GV, 6(2), pp. 641-644.

Warat, L. A. (1982). Saber crítico e senso comum teórico dos juristas. Sequência, 3(5), pp. 48-57.

Zanitelli, L. M. (2011). A reciprocidade nos contratos: uma análise expressivista. Rev. Direito GV, 7(1), pp. 177-196.

Data de submissão/Submission date: 10.10.2016.

Data de aceitação para publicação/Acceptance date:

30.11.2016. 